\title{
Exploring strategies to reach individuals of Turkish and Moroccan origin for health checks and lifestyle advice: a mixed- methods study
}

Andrea J. Bukman ${ }^{1 *}$, Dorit Teuscher², Jamila Ben Meftah ${ }^{3}$, Iris Groenenberg ${ }^{3}$, Mathilde R. Crone ${ }^{3}$, Sandra van Dijk ${ }^{3,4}$, Marieke B. Bos ${ }^{5}$ and Edith J. M. Feskens ${ }^{1}$

\begin{abstract}
Background: Low participation rates among ethnic minorities in preventive healthcare services are worrisome and not well understood. The objective of this study was to explore how adults of Turkish and Moroccan origin living in the Netherlands, aged 45 years and older, can be reached to participate in health checks for cardio-metabolic diseases and follow-up (lifestyle) advice.

Methods: This mixed-methods study used a convergent parallel design, to combine data of one quantitative study and three qualitative studies. Questionnaire data were included of 310 respondents, and interview data from 22 focus groups and four individual interviews. Participants were recruited via a research database, general practitioners and key figures. Quantitative data were analysed descriptively and qualitative data were analysed using a thematic approach.

Results: Regarding health checks, $50 \%(95 \%$ Cl 41;59) of the Turkish questionnaire respondents and $66 \%$ (95\% $\mathrm{Cl} 57 ; 76)$ of the Moroccan questionnaire respondents preferred an invitation from their general practitioner. The preferred location to fill out the health check questionnaire was for both ethnic groups the general practitioner's office or at home, on paper. Regarding advice, both groups preferred to receive advice at individual level rather than in a group, via either a physician or a specialised healthcare professional. It was emphasised that the person who gives lifestyle advice should be familiar with the (eating) habits of the targeted individual. Sixty-one percent ( $95 \% \mathrm{Cl} 53 ; 69)$ of the Turkish respondents preferred to receive information in their native language compared to $37 \%$ (95\% Cl 29;45) of the Moroccan respondents. Several participants mentioned a low proficiency in the local language as an explanation for their preference to fill out the health check questionnaire at home, to receive advice from an ethnic-matched professional, and to receive information in their native language.

Conclusions: The general practitioner is considered as a promising contact to reach adults of Turkish and Moroccan origin for health checks or (lifestyle) advice. It might be necessary to provide information in individuals' native language to overcome language barriers. In addition, (lifestyle) advice must be tailored. The obtained insight into preferences of Turkish and Moroccan adults regarding reach for preventive healthcare services could help professionals to successfully target these groups.
\end{abstract}

Keywords: Mixed-methods, Ethnic groups, Health check, Lifestyle advice, Reach

\footnotetext{
* Correspondence: sandra.bukman@wur.nl

'Division of Human Nutrition, Wageningen University, P.O Box 8129, 6700 EV

Wageningen, The Netherlands

Full list of author information is available at the end of the article
} 


\section{Background}

Cardio-metabolic diseases, like cardiovascular diseases and diabetes mellitus, have a substantial impact on the global burden of disease $[1,2]$. The risk for developing cardio-metabolic diseases seems to be especially high among some ethnic minorities [3-5].

In the Netherlands, as in several other European countries, individuals of Turkish and Moroccan origin are the two largest non-Western ethnic minority groups [6]. Among these ethnic minorities, the prevalence of type 2 diabetes is relatively high compared to the host population [7-9]. There is also evidence for relatively unfavourable HDL cholesterol levels among people of Turkish origin [8].

An increased risk of cardio-metabolic diseases can be due partly to modifiable risk factors, such as an unhealthy lifestyle and overweight $[10,11]$. In the Netherlands, individuals of Turkish and Moroccan origin have a relatively high prevalence of physical inactivity and overweight compared to individuals of Dutch origin $[12,13]$. Given their elevated risk, these groups in particular could benefit from preventive health services.

However, it seems difficult to reach ethnic minorities for preventive health services. The lack of reach hinders both the identification of individuals at high risk and the subsequent uptake of health promoting activities. Firstly, concerning identification, ethnic minorities are often not reached for health screening services [14-17]. This poses a problem, as early detection of individuals at risk for metabolic diseases is of utmost importance in order to prevent health complications and to offer lifestyle advice to those who need it. Secondly, ethnic minorities are less likely to be reached by health promoting activities $[18,19]$. However, the problem does not seem to be that ethnic minorities do not have access to healthcare, as in the Netherlands they often visit their GP [20]. Still, there is a lack of specific strategies to reach individuals of Turkish and Moroccan origin for preventive health services.

Recently, a health check for cardio-metabolic diseases was developed in the Netherlands. This health check consists of a two-stage approach. In the first stage, people fill out a short questionnaire (risk estimation). In the second stage, people with a high risk score are advised to plan two consultations with their GP or practice nurse for further examination of their risk profile and to discuss follow-up actions [21]. Along with the development of this health check, the issue was raised how to reach individuals of Turkish and Moroccan origin for this initiative and how to provide suitable follow-up lifestyle advice. To solve this issue, several studies were initiated. The ambition of this paper was to combine insights of these independent studies, which included one quantitative study and three qualitative studies.

The overall aim of the current study was to get insight into the perceptions of adults of Turkish and Moroccan origin living in the Netherlands regarding how they could successfully be reached for both a health check for cardio-metabolic diseases and follow-up (lifestyle) advice. To this end, this study provided answers to the following questions among the two ethnic groups:

- By whom do they prefer to be invited for a health check, and why?

- Where do they prefer to fill out a health check questionnaire, and why?

- By whom do they want to receive (lifestyle)advice, and why?

- What is the preferred way of communicating (lifestyle)advice, and why?

- What is the preference regarding language, and why?

\section{Methods}

The current study is a secondary analysis, using data from four related studies (one quantitative study and three qualitative studies), among adults of Turkish and Moroccan origin living in the Netherlands. To answer the research questions of the current study, a selection of data of the four studies were used. The relation between the original studies and the data used in the current study is presented in Table 1 . The studies were conducted independently of one another and all provided data regarding either participating in a health check or receiving (lifestyle) advice, or both. A mixedmethods approach - "in which elements of quantitative and qualitative research approaches are combined" [22] - was used in order to get a better understanding of the quantitative results regarding the research questions of the current study, with the help of the narratives from the qualitative studies.

\section{Study population and data collection}

The demographic characteristics of the study population included in the current mixed method study are presented in Table 2. Study population, study procedure, and the data collection methods for each original study are described below. Additionally, for each study, it is described which data is used in the current mixed methods study.

\section{Quantitative study}

Study population The target group of the original study consisted of adults of Turkish and Moroccan origin aged 18 years and older. 
Table 1 Overview of objectives and methods of the original studies and data used in current study

\begin{tabular}{|c|c|c|c|c|c|c|}
\hline & Original study objective & Original study population & Data collection & Recruitment strategy & $\begin{array}{l}\text { Data included in } \\
\text { secondary analysis }\end{array}$ & $\begin{array}{l}\text { Relevant topics } \\
\text { for secondary } \\
\text { analysis }\end{array}$ \\
\hline $\begin{array}{l}\text { Quantitative } \\
\text { study }\end{array}$ & $\begin{array}{l}\text { To get insight into knowledge and } \\
\text { perceptions of adults of Turkish and } \\
\text { Moroccan origin regarding cardiovascular } \\
\text { diseases and its risk factors, and their } \\
\text { preferences in order to reach them with } \\
\text { health communication. }\end{array}$ & $\begin{array}{l}\text { Individuals of Turkish and } \\
\text { Moroccan origin (18 years } \\
\text { and older) }\end{array}$ & $\begin{array}{l}\text { Face-to-face interviews, } \\
\text { using a structured } \\
\text { questionnaire }\end{array}$ & $\begin{array}{l}\text { Via TNS NIPObase } \\
\text { (database for market research) }\end{array}$ & $\begin{array}{l}310 \text { respondents, aged } \\
45 \text { and older: } \\
\text { - } 167 \text { Turks } \\
\text { - } 143 \text { Moroccans }\end{array}$ & $\begin{array}{l}\text { Health check: } \\
\text { - by whom? } \\
\text { - where? } \\
\text { CVD information: } \\
\text { - by whom? } \\
\text { - preferred way? } \\
\text { - preferred } \\
\text { language? }\end{array}$ \\
\hline \multirow[t]{2}{*}{$\begin{array}{l}\text { Qualitative } \\
\text { study I }\end{array}$} & \multirow{2}{*}{$\begin{array}{l}\text { To explore determinants influencing } \\
\text { vulnerable groups regarding (non-) } \\
\text { participation in the Dutch two-stage } \\
\text { cardiometabolic health check, comprising } \\
\text { a health risk assessment and prevention } \\
\text { consultations for high-risk individuals. }\end{array}$} & $\begin{array}{l}\text { Non-Western immigrants and } \\
\text { Dutch individuals with low } \\
\text { socioeconomic status } \\
\text { ( } 45-70 \text { years old) }\end{array}$ & $\begin{array}{l}\text { Focus groups, using a semi- } \\
\text { structured interview guide }\end{array}$ & \multirow[t]{2}{*}{$\begin{array}{l}\text { Via key persons within the } \\
\text { community, e.g. educational } \\
\text { coordinators or employees of } \\
\text { cultural/community } \\
\text { organisations }\end{array}$} & $\begin{array}{l}4 \text { focus groups: } \\
\cdot 2 \text { Turkish groups } \\
\text { - } 2 \text { Moroccan groups }\end{array}$ & \multirow[t]{2}{*}{$\begin{array}{l}\text { Health check: } \\
\text { - by whom? } \\
\text { - where? } \\
\text { - preferred } \\
\text { language? }\end{array}$} \\
\hline & & $\begin{array}{l}\text { Adult children of the non- } \\
\text { Western immigrants } \\
\text { (18-45 years old) }\end{array}$ & $\begin{array}{l}\text { Focus groups, using a semi- } \\
\text { structured interview guide }\end{array}$ & & $\begin{array}{l}5 \text { focus groups: } \\
\cdot 3 \text { Turkish groups } \\
\cdot 2 \text { Moroccan groups }\end{array}$ & \\
\hline \multirow[t]{2}{*}{$\begin{array}{l}\text { Qualitative } \\
\text { study II }\end{array}$} & \multirow{2}{*}{$\begin{array}{l}\text { To explore factors that play a key role in } \\
\text { the uptake and maintenance of } \\
\text { behavioural changes in individuals from } \\
\text { non-western immigrant populations with } \\
\text { a high risk for cardiometabolic disease. } \\
\text { Furthermore to get insight in what kind } \\
\text { of support is needed to increase the } \\
\text { uptake and maintenance of healthy } \\
\text { behaviours. }\end{array}$} & $\begin{array}{l}\text { Non-Western immigrants at risk } \\
\text { for cardio-metabolic diseases } \\
\text { ( } 45-70 \text { years old) }\end{array}$ & $\begin{array}{l}\text { Face-to-face interviews, } \\
\text { using a semi-structured } \\
\text { interview guide }\end{array}$ & Via their GP & $\begin{array}{l}4 \text { face-to-face } \\
\text { interviews: } \\
\cdot 2 \text { Turks } \\
\cdot 2 \text { Moroccans }\end{array}$ & \multirow{2}{*}{$\begin{array}{l}\text { Lifestyle advice: } \\
\text { - by whom? } \\
\text { - preferred way? } \\
\text { - preferred } \\
\text { language? }\end{array}$} \\
\hline & & $\begin{array}{l}\text { Adult children of the non- } \\
\text { Western immigrants } \\
\text { (18-45 years old) }\end{array}$ & $\begin{array}{l}\text { Focus groups, using a semi- } \\
\text { structured interview guide }\end{array}$ & $\begin{array}{l}\text { Via community workers and } \\
\text { neighbourhood centres }\end{array}$ & $\begin{array}{l}3 \text { focus groups: } \\
\cdot 1 \text { Turkish group } \\
\cdot 2 \text { Moroccan groups }\end{array}$ & \\
\hline $\begin{array}{l}\text { Qualitative } \\
\text { study III }\end{array}$ & $\begin{array}{l}\text { To explore perceptions on healthy eating } \\
\text { and physical activity of individuals with } \\
\text { lower socioeconomic status of different } \\
\text { ethnic origin, in order to identify } \\
\text { opportunities to make a lifestyle } \\
\text { intervention more applicable to the } \\
\text { target groups' realities. }\end{array}$ & $\begin{array}{l}\text { Individuals of Turkish, Moroccan } \\
\text { and Dutch origin with low } \\
\text { socioeconomic status } \\
\text { ( } 45 \text { years and older) }\end{array}$ & $\begin{array}{l}\text { Focus groups, using a semi- } \\
\text { structured interview guide }\end{array}$ & $\begin{array}{l}\text { Via local community workers, } \\
\text { chairmen of mosques and } \\
\text { persons of the target population }\end{array}$ & $\begin{array}{l}10 \text { focus groups: } \\
\text { - } 6 \text { Turkish groups } \\
\text { - } 4 \text { Moroccan groups }\end{array}$ & $\begin{array}{l}\text { Lifestyle advice: } \\
\text { - by whom? } \\
\text { - preferred way? } \\
\text { - preferred } \\
\text { language? }\end{array}$ \\
\hline
\end{tabular}


Table $\mathbf{2}$ Characteristics of the participants in the four individual studies in this mixed methods study

\begin{tabular}{|c|c|c|c|c|c|c|c|c|}
\hline & \multicolumn{2}{|c|}{ Quantitative study } & \multicolumn{2}{|c|}{ Qualitative study I } & \multicolumn{2}{|c|}{ Qualitative study II } & \multicolumn{2}{|c|}{ Qualitative study III } \\
\hline & Turks & Moroccans & Turks & Moroccans & Turks & Moroccans & Turks & Moroccans \\
\hline Target group & $n=167$ & $n=143$ & $n=15$ & $n=18$ & $n=2$ & $n=2$ & $n=33$ & $n=33$ \\
\hline \multicolumn{9}{|l|}{ Gender } \\
\hline $\begin{array}{l}\text { Males } \\
\text { Females }\end{array}$ & $\begin{array}{l}51 \% \\
49 \%\end{array}$ & $\begin{array}{l}73 \% \\
27 \%\end{array}$ & $\begin{array}{l}1 \text { group } \\
1 \text { group }\end{array}$ & $\begin{array}{l}1 \text { group } \\
1 \text { group }\end{array}$ & $\begin{array}{l}- \\
2 \text { interviews }\end{array}$ & $\overline{2}$ interviews & $\begin{array}{l}3 \text { groups } \\
3 \text { groups }\end{array}$ & $\begin{array}{l}2 \text { groups } \\
2 \text { groups }\end{array}$ \\
\hline Age (mean years $\pm S D$ ) & $53 \pm 8.1$ & $55 \pm 8.7$ & $52 \pm 8.5$ & $54 \pm 6.8$ & $55 \pm 3.5$ & $48 \pm 2.8$ & $49 \pm 8.5$ & $47 \pm 11.8$ \\
\hline Overweight (BMI > 25 kg/m³) & $82 \%$ & $73 \%$ & - & - & - & - & $85 \%$ & $87 \%$ \\
\hline Adult children & & & $n=22$ & $n=10$ & $n=6$ & $n=13$ & & \\
\hline \multicolumn{9}{|l|}{ Gender } \\
\hline $\begin{array}{l}\text { Males } \\
\text { Females } \\
\text { Mixed }\end{array}$ & $\begin{array}{l}- \\
- \\
-\end{array}$ & $\begin{array}{l}- \\
- \\
-\end{array}$ & $\begin{array}{l}1 \text { group } \\
2 \text { groups } \\
-\end{array}$ & $\begin{array}{l}- \\
2 \text { groups } \\
-\end{array}$ & $\begin{array}{l}- \\
- \\
1 \text { group }\end{array}$ & $\begin{array}{l}1 \text { group } \\
1 \text { group } \\
-\end{array}$ & $\begin{array}{l}- \\
- \\
-\end{array}$ & $\begin{array}{l}- \\
- \\
-\end{array}$ \\
\hline Age (mean years $\pm S D$ ) & - & - & $34 \pm 13.4$ & $19 \pm 3.6$ & $31 \pm 12.2$ & $28 \pm 7.7$ & - & - \\
\hline
\end{tabular}

Procedure A representative sample design was composed, based on the background characteristics of the target group (for each ethnic group: by region, gender, age, education) by using data from Statistics Netherlands. On the basis of this design, 600 persons were selected from the TNS NIPObase, which is a database for market research. Selected persons received an invitation by email to fill out a web-based questionnaire. The persons had two and a half weeks to fill in the questionnaire. A reminder was sent after one and a half weeks. The response rate was $52 \%(N=313)$. An additional sample was recruited for face-to-face interviews $(N=586)$. These interviews were conducted in Dutch, using a structured questionnaire similar to the web-based questionnaire. The interviews were held by specialized personnel of a market research agency. The web-based questionnaire was distributed in March 2010 and the face-to-face interviews were conducted between April and June 2010. The research team assessed that, according to the Dutch regulations, no ethical permission was required for this type of research [23].

Questionnaire The questionnaire consisted of 74 questions divided over four topics, namely, questions regarding participants': 1) general characteristics, 2) health and lifestyle, 3) knowledge and attitude towards cardiovascular diseases (CVD) and health checks, and 4) preferences regarding information provision concerning CVD. It was aimed to construct a questionnaire that would take $30 \mathrm{~min}$ to fill in. The questionnaire was self-constructed by a market research agency specialised in the target population. The questionnaire was pre-tested for duration and clarity among eight subjects (4 of Turkish origin and 4 of Moroccan origin) and was adjusted based on the findings of the pre-test.
Data used in secondary analysis For the mixed methods study, data were used of respondents aged 45 years and older, of whom 167 were of Turkish origin and 143 were of Moroccan origin. Data were only used from those questions related to reach for a health check or related to information provision concerning CVD (Table 3). It should be noted that questions regarding a health check were examined only among those respondents that were either 'maybe' or 'definitely' interested in participating in a health check ( $85 \%$ of the Turkish respondents and $71 \%$ of the Moroccan respondents).

\section{Qualitative study I}

Study population The target group of this study consisted of non-Western immigrants and native Dutch participants with a low socioeconomic status (45-70 years old). Although the target group consisted of persons aged 45-70 years, adult children of the non-Western immigrants (18-45 years old) were also invited for this study. This was done to overcome language barriers and because these children often help their parents to find their way around the Dutch healthcare system. Adult children were interviewed about the needs and preferences of their parents. The methods used in this study are presented in detail elsewhere [24].

Procedure Participants were recruited through key persons within the community, e.g. educational coordinators or employees of cultural/community organisations. The focus groups were conducted between February and June 2010. They were held separately for males and females. The focus groups were held in Dutch by the researcher (IG), who was accompanied by an ethnic matched research assistant who took notes and helped 
Table 3 Selected questions from quantitative study

\begin{tabular}{|c|c|}
\hline A health check: & Information concerning CVD: \\
\hline $\begin{array}{l}\text { •In the future, a new health check will be provided that is scientifically } \\
\text { tested. The check starts with a questionnaire. From your answers, it may } \\
\text { emerge, for example, that you have an elevated risk of getting diabetes } \\
\text { and/or cardiovascular diseases. If so, then you will be advised to visit your } \\
\text { GP for further investigation. Would you like to participate in this new } \\
\text { health check? } \\
\square \text { Yes, definitely } \\
\square \text { Yes, maybe } \\
\square \text { No, probably not } \\
\square \text { No, definitely not } \\
\text { If 'Yes, definitely' or 'Yes, maybe': } \\
\text { • By whom would you prefer to be invited for this check? } \\
\square \text { GP } \\
\square \text { Specialist/hospital } \\
\square \text { Municipal institution/Community health service } \\
\square \text { Other } \\
\square \text { Don't know } \\
\text { - Where would you like to fill out this questionnaire? } \\
\square \text { At GP's office } \\
\square \text { At the specialist's/in the hospital } \\
\square \text { At community health service } \\
\square \text { At other medical healthcare provider } \\
\square \text { In the community centre } \\
\square \text { In the mosque } \\
\square \text { At home, with pen and paper } \\
\square \text { Via internet } \\
\square \text { Other } \\
\square \text { No preference }\end{array}$ & $\begin{array}{l}\text { - Suppose that you are interested in information about CVD, where } \\
\text { would you get that information? Mention two most important } \\
\text { information sources. } \\
\square \text { GP } \\
\square \text { Specialist/hospital } \\
\square \text { Community health service } \\
\square \text { Dutch Heart Foundation } \\
\square \text { Internet } \\
\square \text { Library } \\
\square \text { Other } \\
\text { - What is the preferred way of communicating information about CVD? } \\
\square \text { Written via brochure/paper } \\
\square \text { Internet } \\
\square \text { Oral in a group } \\
\square \text { Oral in person } \\
\square \text { Television } \\
\square \text { Other } \\
\text { - Do you want to receive the information about CVD in Dutch or your } \\
\text { native language? } \\
\square \text { Prefer Dutch } \\
\square \text { Prefer native language } \\
\square \text { Does not matter } \\
\text { - Suppose that a person provides information about CVD. } \\
\text { Do you consider it important that this person: } \\
\text {.. is a physician/doctor? } \\
\text {.. is of the same ethnic origin? } \\
\text {... is of the same gender? } \\
\square \text { Very important } \\
\square \text { A little important } \\
\square \text { Not important } \\
\square \text { Not important at all }\end{array}$ \\
\hline
\end{tabular}

the interviewer, if the mastery of the Dutch language of participants was low. The study was approved by the medical ethics committee of Leiden University Medical Center. Participants' verbal informed consent was audio-taped. The interviews were recorded and transcribed verbatim. Interviews transcripts were coded with Atlas.ti 6.2.

Interview guideline A semi-structured interview guide was used, with questions regarding invitation strategies, risk communication and determinants influencing participation in health checks.

Data used for secondary analysis For the mixed methods study, data were used from four focus groups with the target group (2 Turkish groups; 2 Moroccan groups) and five focus groups with the adult children of the target group (3 Turkish groups; 2 Moroccan groups).

\section{Qualitative study II}

Study population The target group of this study consisted of non-Western immigrants (45-70 years old) at risk for cardio-metabolic diseases. Like in qualitative study I, adult children of non-Western immigrants (1845 years old) were also included in the study.
Procedure The older adults were recruited via their GP, and adult children were recruited via community workers and neighbourhood centres. The (focus group) interviews were conducted between February 2011 and January 2012. Focus groups were organised for men and women separately, if the participants preferred that over a mixed group. The (focus group) interviews were held in Dutch by the researcher (JBM). During the focus groups, the researcher was accompanied by a research assistant who took notes and who was ethnically matched if translating was needed. Likewise, if necessary, a translator was present during the face-to-face interviews. The study was approved by the medical ethics committee of Leiden University Medical Center. Participants signed an informed consent form. The interviews were recorded and transcribed verbatim. Interviews transcripts were coded with Atlas.ti 6.2.

Interview guideline A semi-structured interview guide was used, with questions regarding culture and health, the uptake and maintenance of healthy behaviours, and preferences regarding lifestyle guidance.

Data used for secondary analysis For the mixed methods study, data were available from four face-toface interviews with the target group (2 Turks; 2 
Moroccans) and three focus groups with the adult children of the target group (1 Turkish group; 2 Moroccan groups).

\section{Qualitative study III}

Study population The target group of this study consisted of native Dutch participants and participants of Turkish and Moroccan origin, aged 45 years and older. The methods used in the original study are presented in detail elsewhere $[25,26]$.

Procedure The focus groups were conducted between May and November 2011 and were held separately for males and females. Participants were recruited via local community workers, chairmen of mosques and persons of the target population in mostly disadvantaged neighbourhoods. The focus groups were held in Dutch by one of the two researchers (AJB and DT) and the other researcher took notes. If participants could not express their feelings in Dutch, they expressed themselves in their native language and others translated for the researchers. The study was approved by the medical ethics committee of academic hospital Maastricht and Maastricht University (METC azM/UM). Participants gave either written or audio-taped informed consent. The interviews were recorded and transcribed verbatim. Interviews transcripts were coded with Nvivo 9.2.

Interview guideline A semi-structured interview guide was used with questions regarding determinants of a healthy diet and physical activity, and experiences and preferences regarding lifestyle guidance.

Data used for secondary analysis For the mixed methods study, data were used from ten focus groups with the target group (6 Turkish groups; 4 Moroccan groups).

\section{Mixed-methods analysis}

For the secondary data analyses, a mixed-methods approach was used with a convergent parallel design. This mixed-methods study had a quantitative priority, meaning that greater emphasis was placed on the quantitative findings for answering the study question. The qualitative data were used to explain and elaborate on the quantitative findings.

Firstly, the data of the four studies were prepared (e.g. transcribed, coded) independently by each research team that conducted the original study. Secondly, the first author (AJB) studied the quantitative data. Quantitative data were analysed with SPSS Statistics 22. Data were described using frequency tables. A bootstrap analysis with 1000 simulations was used to calculate $95 \%$ confidence intervals. Data were compared between participants of Turkish and Moroccan origin using ChiSquare tests. Thirdly, the three research teams of the qualitative studies I, II \& III used their qualitative data to explain the findings of the quantitative data. Finally, the first two authors (AJB and DT) compared and combined the results of the previous step. During this process, the original data were consulted when necessary. The final results were checked by all research teams to ensure that no information was missed or misinterpreted.

\section{Results}

\section{Health check}

Regarding reach for a health check, the following topics were examined: preferred source of invitation and preferred location to fill out a health check questionnaire.

\section{Source of invitation}

As described in Table 4, most of the questionnaire respondents would prefer to be invited for a health check by their GP (50\% (95\% CI 41;59) of the Turkish respondents and $66 \%$ (95\% CI 57;76) of the Moroccan respondents). Several participants in the qualitative studies explained that they trust their GP and take it seriously when a GP sends them something. They indicated that, if they were invited by the GP, they would participate.

"If you receive it from the GP, you will fill it out, I'm sure of that. Because if it is from the GP, they will think: Yes." (Turkish female adult child)

However, not everyone trusts their GP. Some participants indicated that they do not have the feeling that their health complaints are taken seriously.

\section{"When you are at the GP, she already starts writing: paracetamol, while you're telling your story." \\ (Turkish male)}

\footnotetext{
"They send us home with a paracetamol, while it [the complaint] is really more severe. They [my parents] won't be taken seriously."

(Moroccan female adult child)
}

Forty-one percent $(95 \%$ CI 32;50) of the respondents of Turkish origin indicated medical specialists/the hospital as their preferred source to invite them for a health check, compared to $18 \%$ (95\% CI 10;25) of the respondents of Moroccan origin. An invitation by a specialist or hospital was not extensively discussed in the qualitative studies. If the invitation was from the hospital, some participants stated that it would be important that they were familiar with that hospital. 
Table 4 Preferences regarding source of invitation and location to fill out a health check questionnaire. The table presents the percentage (with $95 \%$ confidence interval) of participants that chose that option; one option should be chosen

\begin{tabular}{lll}
\hline & Turks $(n=142)$ & Moroccans $(n=102)$ \\
\hline By whom would participants like to be invited for a health check & & \\
GP & $50 \%(41 ; 59)$ & $66 \%(57 ; 76)$ \\
Specialist/hospital & $41 \%(32 ; 50)$ & $18 \%(10 ; 25)$ \\
Municipal institution/Community health service & $2 \%(0 ; 5)$ & $7 \%(2 ; 12)$ \\
Other & $0 \%$ & $5 \%(1 ; 10)$ \\
Don't know & $7 \%(3 ; 12)$ & $5 \%(1 ; 9)$ \\
Preferred location to fill out a health check questionnaire & & $39 \%(30 ; 49)$ \\
At GP's office & $40 \%(32 ; 48)$ & $23 \%(15 ; 30)$ \\
At home, with pen and paper & $23 \%(16 ; 29)$ & $13 \%(6 ; 19)$ \\
At the specialist's/in the hospital & $20 \%(14 ; 27)$ & $9 \%(4 ; 15)$ \\
Via internet & $8 \%(4 ; 14)$ & $2 \%(0 ; 5)$ \\
In the mosque & $2 \%(0 ; 5)$ & $0 \%$ \\
In the community centre & $1 \%(0 ; 4)$ & $4 \%(1 ; 8)$ \\
At community health service & $0 \%$ & $0 \%$ \\
At other medical healthcare provider & $0 \%$ & $2 \%(0 ; 5)$ \\
Other & $1 \%(0 ; 2)$ & $9 \%(3 ; 15)$ \\
No preference & $5 \%(1 ; 9)$ & $0.48^{b}$ \\
\hline
\end{tabular}

* $p$-value of Pearson Chi-Square tests

a The categories 'Other' and ' Don't know' were combined in order to comply to the assumptions of the Pearson Chi-Square test

'The categories 'In the mosque', 'In the community centre', 'At community health service,' 'At other medical healthcare provider' and 'Other' were combined to comply to the assumptions of the Pearson Chi-Square test

"They have to be familiar with it. If it comes from a hospital that they don't know, I would also say: 'What do you want from me'. You put it [the invitation] away and you forget about it." (Turkish female adult child)

\section{Preferred location to fill out the health check questionnaire} Most respondents in the quantitative study indicated that they would prefer to fill out a health check questionnaire at the GP's office (40\% (95\% CI 32;48) of the Turkish respondents and $39 \%(95 \%$ CI 30;49) of the Moroccan respondents). Participants in the qualitative studies explained that, at the GP's office, the GP could tell them about the test and give more information when necessary. Another reason to fill out the questionnaire at the GP's office is because they have time anyway, while waiting for their appointment.

"In the waiting room, persons are bored anyway. The GP can provide the questionnaires in the waiting room. Those persons can fill out the questionnaire on site." (Turkish female adult child)

The preference for filling out the health check questionnaire at home, on paper, was mentioned by $23 \%$ (95\%CI 16;29) of the Turkish questionnaire respondents and $23 \%$ (95\% CI 15;30) of the Moroccan respondents. Participants in the qualitative studies explained that the advantage of receiving a letter at home was that they could take the time to read and understand the letter, or they could ask someone else to translate it for them.

"Personally I prefer a letter. It is better for people who do not speak Dutch. Why? Because if they receive a letter, they will think: 'Oh, I received a letter so I will go to my cousin who does speak Dutch and he can read and translate the letter for me'. They will understand the message better."

(Turkish male adult child)

Some participants in the qualitative studies suggested providing the questionnaire in their mother tongue possibly in addition to the Dutch version - to be able to understand it themselves and not to be dependent on others for a translation. However, even if the questionnaire is provided in the person's mother tongue, some persons might not be able to read it.

"When I look at my own situation, it does not add any value if it is in Arabic, because my mother is illiterate." (Moroccan female adult child) 


\section{Advice}

Regarding reach for follow-up (lifestyle) advice, the following topics were examined: preferred way to receive advice, source of advice and language. It should be noted that the quantitative findings refer to advice regarding CVD in general, whereas the qualitative findings refer to advice regarding lifestyle specifically.

\section{Preferred way to receive advice}

As mentioned by $65 \%$ (95\% CI 57;72) of the Turkish respondents and $51 \%$ (95 \% CI 42;60) of the Moroccan respondents, the preferred way to receive information about CVD was in person, on an individual level (see Table 5). In one of the qualitative studies, it was asked how participants would prefer to receive nutrition and physical activity advice. The answers depended on the type of information that would be expected; in the case of personal information, some participants in the qualitative studies expressed a preference for advice on an individual level because not everyone should know about their personal eating habits:

"If you talk about my lifestyle in particular, yes, then it is nice of course [to discuss it on an individual level]. Otherwise, everyone knows 'oh, he has such a belly, because he eats that and that'. That is not pleasant of course. That advice, when it is about changing my lifestyle for example, then not everyone has to know that." (Moroccan male)

However, in the case of general information, group meetings were appreciated. Participants indicated that receiving general advice in group meetings was better because they could stimulate and support one another.

Table 5 Preferences regarding way of communicating CVD advice. The table presents the percentage (with $95 \%$ confidence interval) of participants that chose that option; multiple options were possible

\begin{tabular}{llll}
\hline & Turks $(n=167)$ & Moroccans $(n=143)$ & $p^{*}$ \\
\hline Where would you get information & & \\
GP & $78 \%(72 ; 85)$ & $76 \%(70 ; 82)$ & 0.68 \\
Specialist/hospital & $44 \%(37 ; 52)$ & $40 \%(31 ; 47)$ & 0.49 \\
Internet & $23 \%(17 ; 29)$ & $17 \%(11 ; 24)$ & 0.26 \\
Dutch Heart Foundation & $11 \%(6 ; 16)$ & $8 \%(5 ; 13)$ & 0.56 \\
Community health service & $7 \%(4 ; 12)$ & $6 \%(2 ; 9)$ & 0.65 \\
Library & $1 \%(0 ; 3)$ & $1 \%(0 ; 4)$ & 1.00 \\
Other & $4 \%(1 ; 7)$ & $14 \%(9 ; 20)$ & 0.004 \\
Preferred way of receiving information & & \\
Oral in person & $65 \%(57 ; 72)$ & $51 \%(42 ; 60)$ & 0.021 \\
Written via brochure/paper & $39 \%(32 ; 47)$ & $43 \%(36 ; 51)$ & 0.49 \\
Oral in a group & $21 \%(15 ; 27)$ & $12 \%(7 ; 17)$ & 0.034 \\
Internet & $19 \%(13 ; 25)$ & $23 \%(16 ; 30)$ & 0.40 \\
Television & $13 \%(8 ; 18)$ & $12 \%(7 ; 17)$ & 1.00 \\
Other & $1 \%(0 ; 2)$ & $5 \%(2 ; 9)$ & 0.026 \\
\hline
\end{tabular}

* $p$-value of Fisher's Exact tests

\section{Source of advice}

When asked for the two most important sources for information about CVD, most of the respondents indicated that they would get their information from their GP $(78 \%$ (95 \% CI 72;85) of the Turkish respondents and $76 \%$ (95\% CI 70;82) of the Moroccan respondents) or a medical specialist/hospital (44\% (95\% CI $37 ; 52$ ) and $40 \%$ (95\% CI 31;47), respectively) (see Table 5). To most of the respondents, it is a little to very important that the person who gives advice is a physician/doctor (90\% (95\% CI 85;94) and $83 \%$ (95 \% CI 77;89) for Turks and Moroccans, respectively) (see Fig. 1). For the participants in the qualitative studies, it was especially important that the person giving advice was competent. Specialised health professionals were suggested, such as a dietician for nutrition advice.

"Preferably someone who knows a lot about that, someone who's professional in that field."

(Turkish female)

Furthermore, it was emphasised that the person who gives lifestyle advice should be familiar with the eating habits of the targeted individual.

"But the person has to have knowledge about our dietary habits, what we eat and so on. Because if the advice is like a plate cut in thirds with potatoes, meat and vegetables [typical Dutch meal], then it won't be successful. Not in our culture." (Turkish male)

Preferences regarding the advisor's ethnicity varied among respondents in the quantitative study. About half of the Turkish respondents (55\% (95\% CI 48;63)) and of the Moroccan respondents (46\% (95\% CI 38;54)) found it a little to very important that the person that provides information has the same ethnicity as the recipient (see Fig. 1). An advantage of ethnicity-matched professionals is, as stated in the qualitative data, that a person speaks the same language.

"Of Turkish origin is easier, right? Then you understand more, so you will know more. You get more information, right?" (Turkish female)

Some participants in the qualitative studies were, however, sceptical towards a person from their own cultural background, because they were afraid of gossip within the community.

"At the end of the day, they rather prefer not to have a Moroccan counsellor, because they don't want to air their dirty laundry in public." (Moroccan male) 
- Very important $\square$ A little important

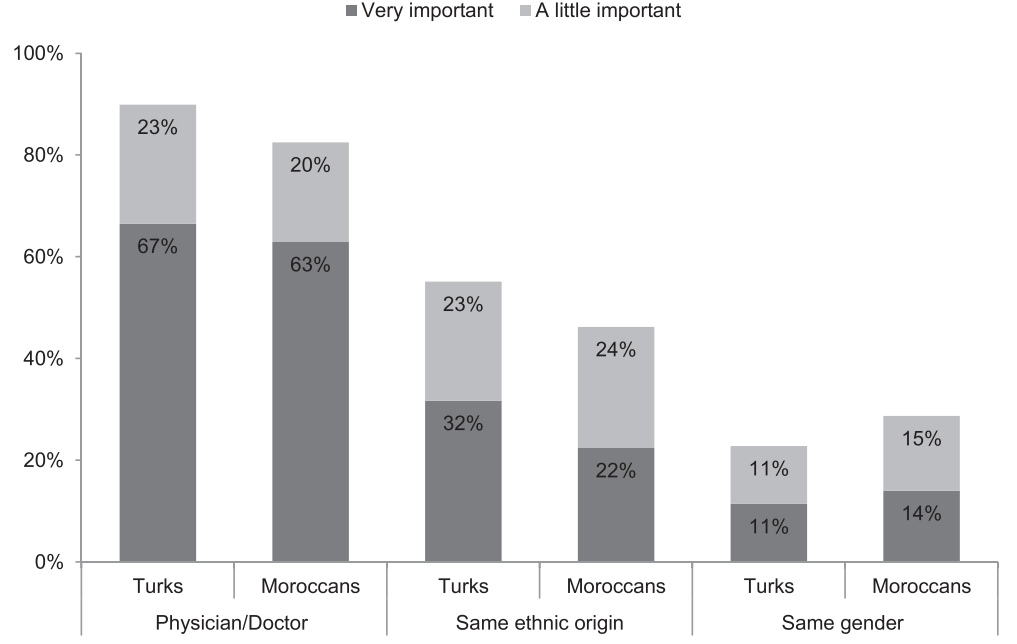

Fig. 1 Preferences regarding profession, ethnicity and gender of the person that provides information about CVD. The figure presents the percentage of Turkish and Moroccan participants that considered it either 'very important' or 'a little important' that the person that provides information is a physician/doctor, of the same ethnic origin and of the same gender. The rest of the participants considered these characteristics of the advisor 'not important' or 'not important at all'

Twenty-three percent (95\% CI 16;29) of the Turkish respondents and $29 \%(95 \%$ CI 22;36) of the Moroccan respondents found it a little to very important that the information provider was of the same gender. In particular, some female participants in the qualitative studies explained why gender-matching is important. The following quotes illustrate that some women would be hesitant to talk with a male advisor and would feel better understood by a female advisor.

Woman 1: "We think women are always better.

Women are also more sociable."

Woman 2: "Being embarrassed for men. Can't say everything."

Woman 1: "Women do understand each other better than men." (Turkish females)

\section{Language}

The preferred language for information materials differed between participants of Turkish and Moroccan origin (Chi-Square $=34.8, p=0.000)$. Twenty-nine percent $(95 \%$ CI 22;36) of the Turkish respondents and $25 \%(95 \%$ CI 18;32) of the Moroccan respondents did not have a preference about receiving information materials in either the local language or their native language. The majority of Turkish respondents, however, wanted to receive information in Turkish $(61 \%$ (95\% CI 53;69)). Among the Moroccan respondents, the preferred language was rather divided: $37 \%(95 \%$ CI $29 ; 45)$ preferred their native language, whereas $38 \%$ (95\% CI 30;46) preferred the local language. In the qualitative data, many Turkish and Moroccan participants often stated that they would prefer to get the advice in their mother tongue. A reason why they preferred advice in their mother tongue was that they needed it in order to understand the advice better, as they might be less fluent in the local language than in their mother tongue.

Woman 1: "In their own language it is easier, yes." Woman 2: "They will also take it more seriously, because they hear it themselves, not via another, no, directly." (Moroccan female adult children)

\section{Discussion}

This current mixed-methods study gave valuable insights into what might be needed in order to reach individuals of Turkish and Moroccan origin in the Netherlands for two different activities: a health check and (lifestyle) advice. Although health checks and lifestyle advice are different activities, some common strategies could be identified to increase the reach among Turkish and Moroccan immigrants for preventive health services. The results of this study suggest that the GP may be a promising contact in order to reach these groups and that possible language barriers should be addressed. Table 6 gives an overview of the strategies identified specifically for health checks and lifestyle advice.

The GP was indicated as the most preferred source for both the invitation for the health check and advice about CVD. Involving the GP may be a promising strategy to reach individuals of Turkish and Moroccan origin given that these groups often visit their GP [20], and GPs in the Netherlands, in general, have a positive attitude 
Table 6 Overview of explored strategies to reach Turkish and Moroccan immigrants for preventive health services

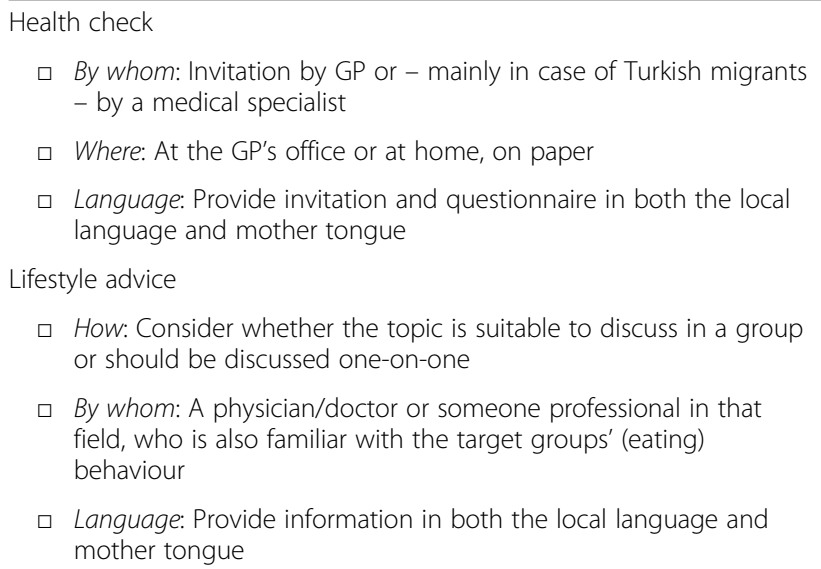

towards primary prevention of cardio-metabolic diseases [27]. However, providing preventive care might not be self-evident in all general practices, and some GPs might consider it a task for other health professionals [28].

A low proficiency in the local language was often used to explain the target groups' preference. A lack of local language skills has been identified as one of the major barriers in reaching minorities for healthcare services [29]. The participants in this mixed-methods study discussed several strategies to overcome language barriers, like offering translated information materials or involving ethnically matched professionals. Although the involvement of ethnically matched professionals can help to overcome language barriers, our participants explained, as also reported in the literature [30], that fear of gossip can be a reason to prefer Dutch professionals over ethnically matched professionals.

In general, the Turkish and Moroccan respondents shared similar preferences. However, it was the respondents of Turkish origin rather than those of Moroccan origin that preferred to be invited for a health check by a medical specialist/hospital. Another notable difference between the two ethnic groups could be seen for preferred language. The preference for information materials in their mother tongue was more prominent among the Turkish respondents than among the Moroccan respondents. This could possibly be explained by differences in proficiency in the local language. Persons with a lower proficiency in the local language find it rather important that leaflets are provided in their mother tongue [31]. In the Netherlands, persons of Turkish origin more often have difficulties with reading Dutch than persons of Moroccan origin [32].

Overall, the findings of this study are in line with previously suggested strategies to reach ethnic minorities for preventive health services [33-35]. Bell and colleagues, for example, concluded that translated information materials and a GP endorsement letter were beneficial in recruiting ethnic minorities for breast screening [33]. An added value of our study is that a mixed-methods approach was used to research how the target groups want to be reached for preventive health services. It was therefore possible not only to quantitatively identify the target groups' preferences, but also to qualitatively explain their preferences, and this helps us to better understand why these specific strategies are necessary. This study identified promising strategies for health professionals how to reach an underrepresented group for preventive healthcare services. It is, however, important to find out how feasible it is to meet the target groups' preferences in practice, as for example time and financial constraints could play a role in the implementation of these strategies.

The current study focused mainly on the preferred source, location and language required to reach the target groups. However, in relation to health checks or lifestyle advice, as stated by some participants in this study, it is also important that the content suits the needs and behaviours of the targeted individuals. Therefore, in our efforts to effectively reach these groups, it is also necessary to get insight into the target groups' preferences regarding the content of health checks or lifestyle advice.

Some methodological concerns should be taken into consideration regarding the interpretation of the results. Although a representative sample design was used to recruit respondents for the quantitative study, more Moroccan men than women participated in it. Therefore, it could be argued that the answers are not representative of the general 45+ Moroccan population in the Netherlands. However, differences between the answers of the Moroccan men and women were small and weighing the data for gender did not change the results substantially (data not shown).

The current study used existing data, which is an advantage, as mixed methods research can be expensive and time consuming. A disadvantage is that the four studies were not designed for answering the research questions of the current study. As a consequence, the topics and study population of the four original studies were not completely comparable. For example regarding advice, the quantitative study focused mainly on advice regarding CVD, whereas the qualitative studies focused on advice regarding healthy eating and physical activity. CVD is a medical condition, and this might explain why the quantitative data merely showed that the GP should give the advice. It could be that, for lifestyle advice specifically, other information sources are preferred. From the qualitative data, it appeared that it is at least important that the information source for lifestyle advice is someone professional or specialised. 
The persons in the quantitative study were partly selected via a database consisting of persons who participate in research fairly regularly. It can be speculated that persons who are used to participating in research, especially in the case of questionnaires, are more likely to have higher literacy skills in the local language. As a consequence, in the quantitative study, the preference for information materials in one's native language and the importance of ethnicity matching in order to overcome language barriers might be under-recognised.

In the mixed-methods approach, it was chosen to give a quantitative priority, meaning that greater emphasis was placed on the quantitative findings for answering the study question. The qualitative data were used to explain and elaborate on the quantitative findings. As the quantitative data were leading in the analysis, one might have missed valuable qualitative data along the way. In the quantitative study, participants were limited to the given answer categories. As a consequence, it could be, for example, that other sources beside the GP are important for the target group, but were missed in the current study as they were not present in the posed answer categories of the quantitative study.

\section{Conclusions}

This study gave important insights into preferences of adults of Turkish and Moroccan origin relating to health checks and lifestyle advice, and reveals some promising strategies to reach these ethnic minorities for preventive healthcare services. The GP is considered as a promising contact to reach Turkish and Moroccan adults in the Netherlands for health checks and lifestyle advice. It might be necessary to provide information in individuals' native language to overcome language barriers. In addition, the content of (lifestyle) advice must be tailored. The obtained insight into the preferences of Turkish and Moroccan adults regarding reach for preventive healthcare services could help professionals to successfully target these groups. It is important to find out how feasible it is to meet the target groups' preferences in practice.

\section{Acknowledgments}

We thank all the participants in the four studies. We also thank research agency Veldkamp for collecting the data for the quantitative study. We thank Linda Pluymen and Roukayya Oueslati for their help with analysing and interpreting the data.

\section{Funding}

The funding body is 'LekkerLangLeven' (cooperation between the Dutch Diabetes Research Foundation, the Dutch Kidney Foundation and the Dutch Heart Foundation) [grant numbers 2008.20.005, 2009.20.010, 2009.20.021]. MBB is employed at the Dutch Heart Foundation (which is a charity fund, a non-profit organisation) and as co-author involved in the design of the study, in the collection of the quantitative data and in writing the manuscript. Except from the involvement of $\mathrm{MBB}$, the funding body was not involved in any stage of this study.

\section{Availability of data and material}

We do not wish to make the data available as we are still using the data for other analyses. However, we are willing to share the data on motivated requests, if researchers have an interest in using our data.

\section{Authors' contributions}

MBB was involved in the design of the quantitative study. IG, MRC and SvD were involved in the design of qualitative study I. JBM, MRC and SvD were involved in the design of qualitative study II. AJB, DT and EJMF were involved in the design of qualitative study III. The data analysis of the separate studies was done in the first instance by the relevant research team. The final mixing of the findings was done by AJB and DT, in close collaboration with the other research teams. The paper was written by AJB and DT and critically revised by all authors. All authors read and approved the final manuscript.

\section{Competing interests}

The authors declare that they have no competing interests.

\section{Consent for publication}

Not applicable.

\section{Ethics approval and consent to participate}

The current study is a secondary analysis, using data from one quantitative study and three related qualitative studies. Two qualitative studies were approved by the medical ethics committee of Leiden University Medical Center and one qualitative study was approved by the medical ethics committee of academic hospital Maastricht and Maastricht University (METC azM/UM). Participants gave either written or audio-taped informed consent. The research team assessed that, according to the Dutch regulations, no ethical permission was required for the quantitative study.

\section{Author details}

${ }^{1}$ Division of Human Nutrition, Wageningen University, P.O Box 8129, 6700 EV Wageningen, The Netherlands. ${ }^{2}$ Department of Human Biology, Maastricht University Medical Centre+, NUTRIM School for Nutrition, Toxicology and Metabolism, P.O Box 616, 6200 MD Maastricht, The Netherlands. ${ }^{3}$ Department of Public Health and Primary Care, Leiden University Medical Center, Hippocratespad 21, 2300 RC Leiden, The Netherlands. ${ }^{4}$ Health, Medical and Neuropsychology Unit, Faculty of Social and Behavioral Sciences, Leiden University, P.O Box 9555, 2300 RB Leiden, The Netherlands. ${ }^{5}$ Dutch Heart Foundation, P.O Box 300, 2501 CH The Hague, The Netherlands.

Received: 17 November 2015 Accepted: 6 July 2016

Published online: 21 July 2016

\section{References}

1. Lopez AD, Mathers CD, Ezzati M, Jamison DT, Murray CJL. Global and regional burden of disease and risk factors, 2001: systematic analysis of population health data. Lancet. 2006;367(9524):1747-57.

2. van Dieren S, Beulens JWJ, van der Schouw YT, Grobbee DE, Neal B. The global burden of diabetes and its complications: an emerging pandemic. Eur J Cardiovasc Prev Rehabil. 2010;17(1):S3-8.

3. Agyemang C, Bindraban N, Mairuhu G, van Montfrans G, Koopmans R, Stronks K. Prevalence, awareness, treatment, and control of hypertension among Black Surinamese, South Asian Surinamese and White Dutch in Amsterdam, The Netherlands: the SUNSET study. J Hypertens. 2005;23(11):1971-7.

4. Oosterberg EH, Devillé WLJM, Brewster LM, Agyemang C, van den Muijsenbergh METC. Chronische ziekten bij allochtonen: handvaten voor patiëntgerichte zorg bij diabetes, hypertensie en COPD [Chronic disease in ethnic minorities: tools for patient-centred care in diabetes, hypertension and COPD]. Ned Tijdschr Geneeskd. 2013;157(16):A5669.

5. Kurian AK, Cardarelli KM. Racial and ethnic differences in cardiovascular disease risk factors: a systematic review. Ethn Dis. 2007;17(1):143-52.

6. Population; sex, age, origin and generation, 1 January [http://statline.cbs.nl/ Statweb/publication/?DM $=$ SLEN\&PA $=37325$ eng \&D $1=0 \& D 2=0 \& D 3=0 \&$ $\mathrm{D} 4=0 \& \mathrm{D} 5=04,102,139,216,231 \& \mathrm{D} 6=16 \& \mathrm{LA}=\mathrm{EN} \& H D R=\mathrm{G} 2, \mathrm{G} 3, \mathrm{G} 5 \& \mathrm{STB}=\mathrm{G} 1, \mathrm{~T}, \mathrm{G} 4$ $\& \mathrm{~W}=$ T]. Accessed 4 March 2015.

7. Uitewaal PJM, Manna DR, Bruijnzeels MA, Hoes AW, Thomas S. Prevalence of type 2 diabetes mellitus, other cardiovascular risk factors, and cardiovascular disease in Turkish and Moroccan immigrants in North West Europe: a systematic review. Prev Med. 2004;39(6):1068-76. 
8. Ujcic-Voortman JK, Baan CA, Seidell JC, Verhoeff AP. Obesity and cardiovascular disease risk among Turkish and Moroccan migrant groups in Europe: a systematic review. Obes Rev. 2012;13(1):2-16.

9. Ujcic-Voortman JK, Schram MT. Jacobs-Van der Bruggen MA, Verhoeff AP, Baan CA: Diabetes prevalence and risk factors among ethnic minorities. Eur J Public Health. 2009;19(5):511-5.

10. Penn L, White M, Lindström J, den Boer AT, Blaak E, Eriksson JG, et al. Importance of weight loss maintenance and risk prediction in the prevention of type 2 diabetes: analysis of European Diabetes Prevention Study RCT. PLoS One. 2013;8(2), e57143.

11. Yusuf PS, Hawken S, Ôunpuu S, Dans T, Avezum A, Lanas F, et al. Effect of potentially modifiable risk factors associated with myocardial infarction in 52 countries (the INTERHEART study): case-control study. Lancet. 2004;364(9438):937-52

12. Ujcic-Voortman JK, Bos G, Baan CA, Verhoeff AP, Seidell JC. Obesity and body fat distribution: ethnic differences and the role of socio-economic status. Obes Facts. 2011:4(1):53-60.

13. Hosper K, Nierkens V, Nicolaou M, Stronks K. Behavioural risk factors in two generations of non-Western migrants: do trends converge towards the host population? Eur J Epidemiol. 2007;22(3):163-72.

14. Vermeer B, van den Muijsenbergh METC. The attendance of migrant women at the national breast cancer screening in the Netherlands 19972008. Eur J Cancer Prev. 2010;19(3):195-8.

15. Dryden R, Williams B, McCowan C, Themessl-Huber M. What do we know about who does and does not attend general health checks? Findings from a narrative scoping review. BMC Public Health. 2012;12(1):723.

16. Klijs B, Otto SJ, Heine RJ, van der Graaf Y, Lous JJ, de Koning HJ. Screening for type 2 diabetes in a high-risk population: study design and feasibility of a population-based randomized controlled trial. BMC Public Health. 2012:12(1):671.

17. Godefrooij MB, van de Kerkhof RM, Wouda PJ, Vening RA, Knottnerus JA, Dinant G-J, et al. Identification of risk factors in primary care: development, implementation and yield of a cardiometabolic health check. Fam Pract. 2012;29:174-81.

18. Brill PA, Kohl HW, Rogers T, Collingwood TR, Sterling CL, Blair SN. The relationship between sociodemographic characteristics and recruitment, retention, and health improvements in a worksite health promotion program. Am J Health Promot. 1991;5(3):215-21.

19. Pagoto SL, Schneider KL, Oleski JL, Luciani JM, Bodenlos JS, Whited MC. Male inclusion in randomized controlled trials of lifestyle weight loss interventions. Obesity. 2012;20(6):1234-9.

20. Stronks K, Ravelli ACJ, Reijneveld SA. Immigrants in the Netherlands: equal access for equal needs? J Epidemiol Community Health. 2001;55(10):701-7.

21. Assendelft WJ, Nielen MM, Hettinga DM, van der Meer V, van Vliet M, Drenthen $\mathrm{A}$, et al. Bridging the gap between public health and primary care in prevention of cardiometabolic diseases; background of and experiences with the Prevention Consultation in The Netherlands. Fam Pract. 2012;29 suppl 1:i126-31.

22. Johnson RB, Onwuegbuzie AJ, Turner LA. Toward a definition of mixed methods research. J Mix Methods Res. 2007;1(2):112-33.

23. Your research: does it fall under the WMO [http://www.ccmo.nl/en/yourresearch-does-it-fall-under-the-wmo]. Accessed 3 February 2015.

24. Groenenberg I, Crone MR, van Dijk S, Gebhardt WA, Ben Meftah J. Middelkoop BJC et al: 'Check it out!' Decision-making of vulnerable groups about participation in a two-stage cardiometabolic health check: a qualitative study. Patient Educ Couns. 2015;98(2):234-44.

25. Teuscher D, Bukman AJ, van Baak MA, Feskens EJM, Renes RJ, Meershoek A. Challenges of a healthy lifestyle for socially disadvantaged people of Dutch, Moroccan and Turkish origin in the Netherlands: a focus group study. Critical Public Health. 2014. doi:10.1080/09581596.2014.962013.

26. Bukman AJ, Teuscher D, Feskens EJM, van Baak MA, Meershoek A, Renes RJ. Perceptions on healthy eating, physical activity and lifestyle advice: opportunities for adapting lifestyle interventions to individuals with low socioeconomic status. BMC Public Health. 2014;14(1):1036.

27. Nielen MMJ, Assendelft WJJ, Drenthen AJM, van den Hombergh $P$, van Dis I, Schellevis FG. Primary prevention of cardio-metabolic diseases in general practice: a Dutch survey of attitudes and working methods of general practitioners. European Journal of General Practice. 2010;16(3):139-42
28. Vos HMM, van Delft DHWJM, De Kleijn MJJ, Nielen MMJ, Schellevis FG, Lagro-Janssen ALM. Selective prevention of cardiometabolic diseases in general practice: attitudes and working methods of male and female general practitioners before and after the introduction of the Prevention Consultation guideline in the Netherlands. J Eval Clin Pract. 2014;20(4):478-85.

29. Scheppers E, van Dongen E, Dekker J, Geertzen J, Dekker J. Potential barriers to the use of health services among ethnic minorities: a review. Fam Pract. 2006;23(3):325-48.

30. Knipscheer JW, Kleber RJ. A need for ethnic similarity in the therapistpatient interaction? Mediterranean migrants in Dutch mental-health care. J Clin Psychol. 2004;60(6):543-54.

31. Lamkaddem M, Spreeuwenberg PM, Devillé WL, Foets MM, Groenewegen PP. Importance of quality aspects of GP care among ethnic minorities: role of cultural attitudes, language and healthcare system of reference. Scan J Public Health. 2012:40(1):25-34.

32. te Riele S. Moroccans have fewer problems with the Dutch language than Turks. In: Web magazine. Statistics Netherlands; 2008

33. Bell TS, Branston LK, Newcombe RG, Barton GR. Interventions to improve uptake of breast screening in inner city Cardiff general practices with ethnic minority lists. Ethn Health. 1999;4(4):277-84.

34. Bader A, Musshauser D, Sahin F, Bezirkan H, Hochleitner M. The Mosque Campaign: a cardiovascular prevention program for female Turkish immigrants. Wien Klin Wochenschr. 2006;118(7-8):217-23.

35. Schmidt M, Absalah S, Nierkens V, Stronks K. Which factors engage women in deprived neighbourhoods to participate in exercise referral schemes? BMC Public Health. 2008:8:371.

\section{Submit your next manuscript to BioMed Central and we will help you at every step:}

- We accept pre-submission inquiries

- Our selector tool helps you to find the most relevant journal

- We provide round the clock customer support

- Convenient online submission

- Thorough peer review

- Inclusion in PubMed and all major indexing services

- Maximum visibility for your research

Submit your manuscript at www.biomedcentral.com/submit 